factors associated with prevalent and incident BV in women and their sexual partners. Data from the cross-sectional study will be presented.

Methods WSW were recruited using internet, festival and mediabased promotion and were ineligible if they are postmenopausal, pregnant or had not had a female sex partner (FSP) in the last 18 months. Study-kits containing consent forms, questionnaires, swabs and slides were sent to participants and returned by post. At baseline, women self-collected three consecutive vaginal swabs and slides at weekly intervals and completed detailed demographic behavioural data via an online or paper-based questionnaire. Gramstained self-collected vaginal smears (SCVS) were scored by the Nugent method. Women were classified as having prevalent BV if $\geq 1$ slides had a Nugent score (NS) of 7-10, intermediate flora if $\geq 1$ slides had a NS $=4-6$ and normal flora if all three slides had a $\mathrm{NS}=0-3$. Univariate and multivariate analyses were performed using SPSS to examine the association between BV and behavioural practices.

Results In February 2011, 342 (86\%) women had been recruited and 314 (92\%) women had completed all cross-sectional requirements. Median age was 31 years (range 19-49), 309 (98\%) reported a FSP in the last year, 253 (81\%) had a current sexual partner ( $95 \%$ female) and $246(78 \%)$ reported vaginal sex with a male in the past. The prevalence of BV was $29 \%$ ( $95 \%$ CI $20 \%$ to $38 \%$ ) in women providing $\geq 1$ SCVS. Two hundred and seventy-five (88\%) women provided all three SCVS of which 178 (65\%) had stable normal flora on all slides, $56(20 \%)$ stable BV and $41(15 \%)$ had unstable flora transitioning between $\geq 1$ Nugent categories over the three slides. Multivariate analysis found that being a current smoker of cigarettes or marijuana (Adjusted OR AOR $=2.2 ; 95 \% \mathrm{CI}: 1.3 \%$ to $3.8 \%$ ) and having $>5$ lifetime FSPs (AOR $=1.8 ; 1.0$ to 3.01 ) was significantly associated with prevalent BV. A borderline association with FSP receptive oral sex $(A O R=3.2 ; 0.9$ to 11.0$)$ was evident. $B V$ was not associated with increased age or numbers of male partners.

Conclusion Prevalent BV is common (30\%) in WSW and is strongly associated with smoking and increasing numbers of FSPs but not male partners. A high proportion of WSW had stable vaginal flora $(85 \%)$ over a 3 week period. This study aims to advance our understanding of epidemiology of BV in WSW.

\section{1-S05.04 INCREASED RISK FOR TRICHOMONAS VAGINALIS IN AN URBAN POPULATION OF YOUNG ADULTS}

doi:10.1136/sextrans-2011-050109.28

${ }^{1} \mathrm{~S}$ Rogers, ${ }^{2} \mathrm{C}$ Turner, ${ }^{3} \mathrm{~W}$ Miller, ${ }^{4} \mathrm{~A}$ Roman, ${ }^{3} \mathrm{M}$ Hobbs, ${ }^{1} \mathrm{~S}$ Tan. ${ }^{1}$ Research Triangle Institute, Washington, USA; ${ }^{2}$ City University of New York Flushing, USA; ${ }^{3}$ University of North Carolina, Chapel Hill, USA; ${ }^{4}$ University of Massachusetts, Boston, USA

Background The epidemiology of $T$ vaginalis (TV) in the general population is not well understood, although it is reported to be the most common curable sexually transmitted infection worldwide. Surveillance data do not exist either for US national or local populations. Infection with TV increases the likelihood of HIV acquisition and has been associated with adverse health outcomes in men and women.

Methods The Monitoring STIs Survey Program (MSSP) used telephone audio computer-assisted self-interview technology and specimen collection kits sent out and returned by mail to monitor $T$ vaginalis and $C$ trachomatis among a probability sample of 15 to 35 year-olds residing in Baltimore, MD from September 2006 through June 2009. Specimens were tested using TMA-based APTIMA assays. Weighted estimates of infection prevalence by respondents' sociodemographic and behavioural characteristics were tabulated using poisson regression.
Abstract 01-S05.04 Table 1 Estimated prevalence of trichomoniasis and chlamydial infection by respondent characteristics: monitoring STIs in the population, 2006-09

\begin{tabular}{|c|c|c|c|c|c|}
\hline Characteristic & $\mathbf{N}$ & $\begin{array}{l}\boldsymbol{T} \text { vaginalis } \\
\text { Wtd.\% (95\% CI) }\end{array}$ & p & $\begin{array}{l}\text { C trachomatis } \\
\text { Wtd.\% (95\% Cl) }\end{array}$ & $\mathbf{p}$ \\
\hline Total & 2120 & $7.5(6.0$ to 9.0$)$ & & $3.9(2.7$ to 5.0$)$ & \\
\hline \multicolumn{6}{|l|}{ Sex } \\
\hline Women & 1322 & $11.8(9.6$ to 14.3$)$ & & $3.4(2.4$ to 4.8$)$ & \\
\hline Men & 798 & $2.9(1.6$ to 5.1$)$ & $<0.001$ & $4.5(2.8$ to 7.0$)$ & 0.35 \\
\hline \multicolumn{6}{|l|}{ Race } \\
\hline Black & 1299 & $11.2(9.1$ to 13.6$)$ & & $6.0(4.4$ to 8.1$)$ & \\
\hline Non-black & 821 & 2.0 (1.2 to 3.5$)$ & $<0.001$ & $0.7(0.2$ to 2.0$)$ & $<0.001$ \\
\hline \multicolumn{6}{|l|}{ Age } \\
\hline $15-19$ & 576 & 7.3 (4.7 to 11.2 ) & & $6.6(4.2$ to 10.5$)$ & \\
\hline $20-24$ & 460 & 10.6 (7.6 to 14.7$)$ & & 5.9 (3.6 to 9.7$)$ & \\
\hline $25-29$ & 501 & 5.6 (3.7 to 8.5$)$ & & $1.7(0.8$ to 3.3$)$ & \\
\hline $30-35$ & 583 & 6.6 (4.5 to 9.6$)$ & 0.39 & $1.2(0.5$ to 2.8$)$ & $<0.001$ \\
\hline \multicolumn{6}{|c|}{$3+$ partners past year } \\
\hline Yes & 445 & $10.6(7.6$ to 14.6$)$ & & 8.2 (5.5 to 12.0 ) & \\
\hline No & 1674 & $6.6(5.1$ to 8.4$)$ & 0.02 & 2.7 (1.8 to 4.2$)$ & $<0.001$ \\
\hline \multicolumn{6}{|c|}{ New partner in past 3 months } \\
\hline Yes & 435 & 11.7 (8.2 to 16.4$)$ & & 9.3 , (6.3 to 13.6$)$ & \\
\hline No & 1657 & $6.3,(5.0$ to 8.1$)$ & 0.004 & 2.5 (1.6 to 3.8 ) & $<0.001$ \\
\hline \multicolumn{6}{|l|}{ Previous STI } \\
\hline Yes & 503 & 12.8 (9.6 to 17.0$)$ & & 4.5 (2.7 to 7.2$)$ & \\
\hline No & 1372 & 6.7 (5.2 to 8.8$)$ & 0.001 & $4.3(3.0$ to 6.1$)$ & 0.91 \\
\hline
\end{tabular}

Results 2120 of 2936 respondents (72.2\%) provided specimens for STI testing. The prevalence of TV was $7.5 \%$ (95\% CI $6.0 \%$ to $9.0 \%)$ and was significantly higher among women $(11.8 \%)$ than men $(2.9 \% ; \mathrm{PR}=4.0$, $95 \%$ CI $2.2 \%$ to $7.4 \%$ ). Among Black females, the estimated prevalence was $16.1 \%$ (95\% CI 1.0\% to 19.8). Levels of TV infection ranged from $7.3 \%$ (95\% CI $4.7 \%$ to 11.2$)$ among $15-19$ year olds to $10.6 \%(95 \% \mathrm{CI}$ $7.6 \%$ to 14.7$)$ among those aged $20-24$ years and $6.6 \%(95 \%$ CI $4.5 \%$ to 9.6) among $30-35$ year olds ( $p=0.39$ for linear trend). Infection with $T$ vaginalis was more common than infection with $C$ trachomatis $3.9 \%$, $95 \%$ CI $2.7 \%$ to $5.0 \%$; $<<0.001)$. Unlike TV, CT did not vary by gender (women $4.5 \%$, men $3.4 \%, \mathrm{p}=0.35$ ) and infection prevalence was significantly higher among those $<25$ years of age ( $p<0.001$ for trend). Concomitant TV infection was detected in $23.5 \%$ of respondents with CT ( $\mathrm{PR}=3.7,95 \%$ CI $1.9 \%$ to 7.7$)$. Both TV and CT were associated with reporting of three or more partners in the past year and a new partner in the past 3 months. TV infection, but not CT, was associated with a previous STI diagnosis ( $\mathrm{PR}=1.9,95 \% \mathrm{CI} 1.3 \%$ to $2.8 \%$ ) see Abstract O1-S05.04 table 1.

Conclusions: Undetected $T$ vaginalis is common among young adults in Baltimore, particularly among women. Nearly one-fourth of respondents with chlamydial infection also tested positive for TV. Unlike chlamydial infection, the prevalence of TV was consistently high across all age groups. Our results provide strong support for routine screening for TV in conjunction with CT in populations at elevated risk of infection.

\section{1-S05.05 ASSOCIATION BETWEEN TRICHOMONAS VAGINALIS AND VAGINAL BACTERIAL COMMUNITY COMPOSITION AMONG ASYMPTOMATIC REPRODUCTIVE-AGE WOMEN IN THE USA}

doi:10.1136/sextrans-2011-050109.29

${ }^{1} \mathrm{R}$ Brotman, ${ }^{1} \mathrm{~L} \mathrm{~L}$ Jones, ${ }^{1} \mathrm{~J}$ Sakamoto, ${ }^{1} \mathrm{P}$ Gajer, ${ }^{2} \mathrm{~K}$ Ault, ${ }^{1} \mathrm{~L}$ Peralta, ${ }^{3} \mathrm{~L}$ Forney,

${ }^{3} \mathrm{Z}$ Abdo, 'J Ravel. 'University of Maryland, School of Medicine, Baltimore, USA; ${ }^{2}$ Emory University, School of Medicine, USA; ${ }^{3}$ University of Idaho, USA

Background Vaginal bacterial communities are thought to prevent infection by sexually transmitted organisms. Prior work 
demonstrated that the vaginal microbiota of reproductive-age women in the US cluster into five groups of bacterial communities; four dominated by Lactobacillus spp. (L iners, L crispatus, L gasseri, $L$ jensenii), and one lacking significant numbers of lactobacilli and characterised by higher proportions of strictly anaerobic organisms (termed group IV). We sought to compare the vaginal microbiota of $T$ vaginalis-positive and $T$ vaginalis-negative women using cultivation-independent methods. To our knowledge, this is the first analysis of the relationship between $T$ vaginalis and vaginal bacterial communities characterised by molecular methodologies.

Methods Self-collected vaginal swabs were obtained cross-sectionally from 396 asymptomatic US women equally representing four ethnic/racial groups. Screening for the presence of $T$ vaginalis was performed using PCR targeting the 18S rRNA and $ß$-tubulin genes. Vaginal bacterial composition was characterised by pyrosequencing of barcoded 16S rRNA genes. The relationship between vaginal microbiota and $T$ vaginalis was evaluated by Fisher's exact testing and logistic regression.

Results Of the 11 T vaginalis-positive cases, 8 (72\%) were classified to the low-Lactobacillus group IV, 2 (18\%) and 1 (9\%) with communities dominated by $L$ iners and $L$ crispatus, respectively ( $p$ value: 0.056 ). Group IV was associated with an eightfold increased odds of detecting $T$ vaginalis compared to women with communities dominated by $L$ crispatus (OR: $8.26,95 \%$ CI: $1.07 \%$ to $372.65 \%$, p value: 0.04 ). Other than the major bacteria dominating each cluster, none of the other observed taxa showed significant association with $T$ vaginalis-positivity although this may reflect few observed cases rather than lack of a true association. Ten (91\%) of the T vaginalis cases self-reported Black ethnicity and 1 (9\%) reported Asian, ( $p$ value: 0.00002).

Conclusion Molecular analyses revealed that vaginal microbiota with low proportions of lactobacilli were significantly associated with presence of $T$ vaginalis. Longitudinal studies are needed to identify the causal nature of the relationship between vaginal bacterial communities and STI risk.

\section{1-S05.06 ASSOCIATION BETWEEN PREVALENT BACTERIAL VAGINOSIS (BV) AND HIV INFECTION AMONG FEMALE SEX WORKERS AT TWO AFRICAN AND TWO INDIAN SITES}

doi:10.1136/sextrans-2011-050109.30

\begin{abstract}
${ }^{1} \mathrm{~F}$ Aimé Guédou, ${ }^{2} \mathrm{~L}$ van Damme, ${ }^{3} \mathrm{~F} \mathrm{M}$ Mirembe, ${ }^{4} \mathrm{~S}$ Solomon, ${ }^{5} \mathrm{M}$ Becker, ${ }^{2} \mathrm{~J}$ Deese, ${ }^{6} \mathrm{~T}$ Crucitti, ${ }^{2} \mathrm{D}$ Taylor, ${ }^{1} \mathrm{M}$ Alary. ${ }^{1}$ Centre hospitalier affilié universitaire de Québec, Quebec, Canada; ${ }^{2}$ Family Health International, Durham, USA; ${ }^{3}$ Makerere University, Kampala, Uganda; ${ }^{4}$ Y.R. Gaitonde Center for AIDS Research and Education, Chennai, India; ${ }^{5}$ University of Manitoba, Winnipeg, Canada; ${ }^{6}$ Insitute of Tropical Medicine, Antwerp, Belgium
\end{abstract}

Background BV is the most common female genital infection, particularly in developing countries and reaches its highest prevalence among female sex workers (FSWs). Over the past decade, evidence has accumulated as to its role in HIV acquisition. If BV actually plays such a role, even a modest relative risk would yield an important attributable risk for HIV, particularly in developing countries where FSWs play a pivotal role in the dynamics of HIV epidemics. Yet, data on this association among FSWs are still scanty. We analysed data from high risk women screened prior to participation in a microbicide trial to estimate BV and HIV respective prevalence and to study their association, in the presence or not of other STIs.

Methods Data from Kampala, Cotonou, Chennai and Mudhol/ Jhamkandi sites were analysed. Socio-demographic, behavioural and medical data were collected through individual interviews. Blood was taken for HIV and syphilis antibody testing. Genital samples were collected for BV diagnosis using Nugent scoring system, of gonorrhoea and chlamydias by SDA and of trichomoniasis (TV) and candidiasis on wet mount. Binomial log regression was used to estimate HIV prevalence ratio (PR) in relation to BV. Fitting of multivariable models was done with backward selection using the approach of proportional change of the PR. Product terms from BV and each of other STIs were included in the final model. Significance level was set at $5 \%$ for testing associations and $15 \%$ for interactions.

Abstract 01-S05.06 Table 1 Final multivariate model ${ }^{*}$ describing association between Bacterial vaginosis and HIV infection with effect modification by Trichomoniasis, among 1367 FSWs recruited at 2 African and 2 Indian sites

\begin{tabular}{|c|c|c|c|c|}
\hline Variables & $\begin{array}{l}\text { HIV prevalence by } \\
\text { exposure level: } n_{i} / N_{i}(\%)\end{array}$ & Adjusted $\mathbf{P R}^{\S}$ & $95 \% \mathrm{Cl}$ & p value \\
\hline \multicolumn{5}{|l|}{ Bacterial vaginosis: } \\
\hline Positive & 192/651 (29.49) & 1.25 & 1.05 to 1.48 & 0.01 \\
\hline Negative & $177 / 716(24.72)$ & 1.00 & - & - \\
\hline \multicolumn{5}{|l|}{ Site: } \\
\hline Mudhol/Jhamkandi & $23 / 49(46.94)$ & 1.06 & 0.71 to 1.58 & 0.78 \\
\hline Cotonou & $123 / 447$ (27.52) & 0.63 & 0.50 to 0.79 & $<0.0001$ \\
\hline Chennai & $56 / 355$ (15.77) & 0.50 & 0.33 to 0.76 & 0.001 \\
\hline Kampala (Ref.) & $167 / 516(32.36)$ & 1.00 & - & - \\
\hline \multicolumn{5}{|l|}{ Past history of STI: } \\
\hline Yes & 198/615 (32.20) & 1.43 & 1.21 to 1.70 & $<0.0001$ \\
\hline No & $171 / 752(22.74)$ & 1.00 & - & - \\
\hline \multicolumn{5}{|c|}{ Exerting an occupation besides commercial sex work: } \\
\hline Yes & $243 / 906(26.82)$ & 0.82 & 0.65 to 1.03 & 0.09 \\
\hline No & $126 / 461(27.33)$ & 1.00 & - & - \\
\hline \multicolumn{5}{|c|}{ Current contraceptive method $\dagger:$} \\
\hline Hormonal & $65 / 221(29.41)$ & 0.76 & 0.43 to 1.34 & 0.34 \\
\hline IUD & $3 / 11(27.27)$ & 0.99 & 0.35 to 2.82 & 0.98 \\
\hline Female sterilisation & $43 / 294(14.63)$ & 0.54 & 0.31 to 0.94 & 0.03 \\
\hline Condom & $248 / 809(30.66)$ & 0.89 & 0.53 to 1.50 & 0.67 \\
\hline None (Ref.) & $10 / 31(32.26)$ & 1.00 & - & - \\
\hline \multicolumn{5}{|c|}{ Oral sex in the past 30 days: } \\
\hline Yes & $5 / 30(16.67)$ & 0.58 & 0.35 to 0.95 & 0.03 \\
\hline No & $364 / 1337(27.23)$ & 1.00 & - & - \\
\hline \multicolumn{5}{|l|}{ Age (years): } \\
\hline 15-19 (Ref.) & 10/66 (15.15) & 1.00 & - & - \\
\hline $20-24$ & $100 / 380(26.32)$ & 1.85 & 1.03 to 3.34 & 0.04 \\
\hline $25-29$ & 109/357 (30.53) & 2.23 & 1.24 to 4.00 & 0.01 \\
\hline $30-34$ & 68/221 (30.77) & 2.70 & 1.50 to 4.88 & 0.001 \\
\hline $35-60$ & $82 / 343(23.91)$ & 2.25 & 1.23 to 4.11 & 0.01 \\
\hline \multicolumn{5}{|c|}{ Education duration (years) } \\
\hline $0-6$ & $240 / 782$ (30.69) & 1.00 & - & - \\
\hline $7-12$ & $124 / 548(22.63)$ & 0.76 & 0.63 to 0.92 & 0.005 \\
\hline $13-17$ & $5 / 37(13.51)$ & 0.50 & 0.22 to 1.13 & 0.10 \\
\hline \multicolumn{5}{|l|}{ Gonorrhoea } \\
\hline Positive & $52 / 111(46.85)$ & 1.52 & 1.26 to 1.83 & $<0.0001$ \\
\hline Negative & $316 / 1253$ (25.22) & 1.00 & - & - \\
\hline \multicolumn{5}{|l|}{ Candidiasis: } \\
\hline Positive & $118 / 421(28.03)$ & 1.20 & 0.99 to 1.45 & 0.06 \\
\hline Negative & $251 / 946(26.53)$ & 1.00 & - & - \\
\hline \multicolumn{5}{|l|}{ Syphilisł: } \\
\hline Positive & $29 / 82(35.37)$ & 1.26 & 0.96 to 1.67 & 0.09 \\
\hline Negative & $339 / 1282(26.44)$ & 1.00 & - & - \\
\hline \multicolumn{5}{|l|}{ Trichomoniasisł: } \\
\hline Positive & 29/82 (35.37) & 1.20 & 0.82 to 1.74 & 0.34 \\
\hline Negative & $339 / 1282(26.44)$ & 1.00 & - & - \\
\hline \multirow[t]{2}{*}{ BV_TV ${ }^{\pi}$} & - & 0.61 & 0.32 to 1.13 & 0.12 \\
\hline & & 1.00 & - & - \\
\hline
\end{tabular}

*This model includes, besides the site, all other covariables with $\mathrm{p}$ value $<0.10$ (though removal of neither resulted in a substantial change in the PR estimate during the confounders selection process), as well as TV and the product term between BV and TV. $\dagger=1$ missing value.

$\ddagger=3$ missing values.

$\S P R=$ prevalence ratio

\BV_TV=product term between Bacterial Vaginosis (BV) and Trichomoniasis (TV). 